\title{
Discrepancies in Different Precipitation Data Products in the Bay of Bengal during Summer Monsoon Season
}

\author{
Li Qi ${ }^{1}$ and Yuqing Wang ${ }^{1,2}$ \\ ${ }^{1}$ Collaborative Innovation Center on Forecast and Evaluation of Meteorological Disasters, Key Laboratory of \\ Meteorological Disaster of Ministry of Education, Nanjing University of Information Science \& Technology, Nanjing 210044, China \\ ${ }^{2}$ International Pacific Research Center and Department of Meteorology, University of Hawaii at Manoa, Honolulu, HI 96822, USA
}

Correspondence should be addressed to Yuqing Wang; yuqing@hawaii.edu

Received 16 March 2015; Revised 30 April 2015; Accepted 2 May 2015

Academic Editor: Gwo-Fong Lin

Copyright (C) 2015 L. Qi and Y. Wang. This is an open access article distributed under the Creative Commons Attribution License, which permits unrestricted use, distribution, and reproduction in any medium, provided the original work is properly cited.

\begin{abstract}
In the east Bay of Bengal (BoB), the precipitation maximum always lies near the eastern coast on the windward side of Mountain Araka Yoma in the summer monsoon season. In this study, different precipitation products are compared in terms of their representation of the offshore rainfall maximum feature in this region. Climatologically, all products examined present similar rainfall distribution except for the CMAP. Significant discrepancies among different products are found in the interannual variation, as illustrated by the contrast features between 2002 and 2005. Based on the TRMM products (except for 3B42RT) and GPCP V1.2, the precipitation maximum occurred near the coast in 2002, while it was about 100-200 km offshore in 2005 . However, this difference is not obvious in the GPCP V2.2 and TRMM 3B42RT products. Larger easterly vertical wind shear and warmer SST were present in 2005. Both favor stronger orographically-forced convective systems to propagate offshore, leading to the offshore rainfall maximum in 2005. Therefore, it is suggested that the TRMM 3B40RT, which is mainly based on passive microwave estimates, may be more reliable among different precipitation products in reflecting the precipitation feature in the coastal region of the east $\mathrm{BoB}$.
\end{abstract}

\section{Introduction}

Precipitation is one of the most important climate variables in the study of climate variability and change and also a major component of the earth's water and energy cycles. Reliable precipitation dataset with high spatial and temporal resolution is the key to the understanding of climate and climate variability and the verification of numerical weather prediction and climate simulations. Precipitation is also an important input variable for ocean circulation models as freshwater flux and an input variable for many other application models, such as land surface models and hydrometeorological models. Numerous global precipitation datasets have been developed in the last two decades or so using different data sources, such as in situ observations, satellite estimates, climate model simulations, and/or their combinations.

Because of the lack of sufficient in situ observations, current precipitation estimates over the open oceans are heavily dependent on satellite retrievals, such as the Tropical
Rainfall Measuring Mission (TRMM) satellite. Because of the uncertainties in different retrieval algorithms and the lack of true observations to calibrate the estimates, precipitation products from different data sources show a certain degree of discrepancies, which sometimes are quite large over the tropical and subtropical oceans (e.g., [1-5]). Earlier evaluation of precipitation products has focused mainly on large scale, such as a basin scale over the ocean or continental scales [6]. Rainfall estimates as well as their validations at different time and spatial scales remain a major challenge due to sparse rain gauges in many tropical and subtropical regions.

The TRMM is a joint US-Japan satellite mission to monitor the tropical and subtropical precipitation and to estimate its associated latent heating. The TRMM is the first satellite from which its observations are able to provide detailed and comprehensive datasets on the four-dimensional distribution of rainfall and latent heating over vast tropical and subtropical oceans and continents. It has been widely used in many earth science applications, such as global drought and flood monitoring [7-9], hurricanes and typhoons [10-12], tropical 
climatology [1, 13-18], and verification of climate model simulations (e.g., [19]). Moreover, other satellite precipitation datasets are also broadly applied to the study of tropical climatology, such as the Global Precipitation Climatology Project (GPCP) products and Climate Prediction Center (CPC) Merged Analysis of Precipitation (CMAP).

It is our interest to compare the different precipitation products in the east Bay of Bengal (BoB) in the Asian summer monsoon season. This is motivated by the importance and the special feature of precipitation in this region. The east $\mathrm{BoB}$ is one of the sites with the highest precipitation during summer in the Asian monsoon domain. As the southwesterly monsoon flow impinges on the narrow mountain range of Araka Yoma in Myanmar coast, moist air is forced to rise by the orographic lifting [14]. It gives rise to convection center of monsoon rain along the eastern coast of the BoB, which may be modified by diurnal cycle [20]. Convective heating associated with these mesoscale mountains in South Asia has been demonstrated to contribute largely to the large-scale summer monsoon circulation [14, 21]. Despite the importance of the BoB to both weather and climate in the Asian monsoon domain, the region is poorly sampled and investigated because of the lack of sufficient in situ observations [22]. Convection over the east $\mathrm{BoB}$ is always poorly simulated in most atmospheric models [23] and this in turn further hampers effort at model validation and improvements. It may also affect the understanding of temporal and spatial variations of precipitation in the BoB if the precipitation products are not reliable enough or the features might differ among different datasets.

In this study, different precipitation products are used to document the variation of precipitation in the eastern coastal region in the $\mathrm{BoB}$. The offshore feature of precipitation on the windward side of the mesoscale mountain range in Myanmar is the main focus. We will discuss the discrepancies among different precipitation products in reproducing those features. Because of the lack of in situ observations, we will evaluate the precipitation distribution based on physical reasoning with the large-scale circulation difference that is dynamically responsible for the precipitation features. The rest of the paper is organized as follows. The datasets are described in Section 2. Climatology and interannual variability from different precipitation products are compared in Section 3. Besides TRMM 3B43, GPCP products, and CMAP, TRMM products of 3B40RT, 3B41RT, and 3B42RT are also analyzed in order to identify discrepancies resulting from different types of sensors used. Major conclusions and discussions are given in the last section.

\section{Datasets}

The precipitation products evaluated in this study include three major products, namely, TRMM products (3B40RT, 3B41RT, 3B42RT, and 3B43), GPCP products (versions 1.2 and 2.2), and CMAP. The precipitation datasets and several other data used in our analysis are described below briefly.

2.1. TRMM Products. The TRMM satellite measures rainfall in tropical and subtropical regions by use of the following instruments: precipitation radar (PR), TRMM microwave imager (TMI), and the visible and infrared scanner (VIRS) $[24,25]$. TRMM satellite was successfully launched on November 27, 1997, in Japan. Therefore, all TRMM products are available since 1998. In our analysis, precipitation climatology is the mean from 1998 to 2014.

2.1.1. TRMM Real-Time. The real-time TRMM multisatellite precipitation analysis $[26,27]$ is run quasioperationally on a best-effort basis of the precipitation processing system with ongoing scientific development. The system was developed as a testbed for producing concepts in merging quasiglobal precipitation estimates and it takes advantage of the increasing availability of input datasets in near-real time. Estimates are posted on the web about 6 hours after the observation time.

(a) 3B40RT (High-Quality, HQ). The input to 3B40RT (HighQuality, HQ), on $0.25^{\circ} \times 0.25^{\circ}$ grids and 3 -h averaged, consists of precomputed precipitation estimates of TMI, AMSR-E, SSMI, SSMIS, AMSU-B, and microwave humidity sounder (MHS) based on single satellite passive microwave data. Versions of the Goddard profiling (GPROF) algorithm are applied to create the input estimates from conical-scan passive microwave instruments, and the national environmental satellite data and information service (NESDIS) algorithm for cross-track scan microwave sounders. In common with other physically based algorithms, GPROF employs all available bands from modern conical-scan passive microwave imagers: 7 channels on SSMI and SSMIS and 9 channels on TMI and AMSR-E. The NESDIS algorithm uses 5 "high-frequency" channels and 1 AMSU-A channel from modern cross-trackscanning sounders: AMSU-B and MHS.

(b) 3B41RT (Variable Rain Rates, or VAR). The 3B41RT infrared (IR) precipitation estimate converts $0.25^{\circ} \times 0.25^{\circ}-$ averaged hourly geostationary IR brightness temperature $\left(T_{b}\right)$ to rain rates using spatially and temporally varying calibration by the HQ (3B40RT). The algorithm is a probabilitymatched threshold approach that ensures that the histogram of grid box-average IR precipitation rates matches the histogram of grid box-average HQ precipitation rates locally. As such, the colder an IR pixel is than the zero-precipitation threshold $T_{b}$, the larger the rain rate it receives. It is referred to as the variable rain rate (VAR) IR algorithm.

The input to VAR consists of the TRMM real-time HQ merged passive microwave precipitation estimates and the NOAA CPC merged global geosynchronous 11-micron infrared (geo-IR) $T_{b}$. The latter is provided for the latitude band between $60^{\circ} \mathrm{N}$ and $60^{\circ} \mathrm{S}$ based on merging all available images from GOES-E, GOES-W, MTSAT (previously GMS, GOES-9), METEOSAT 5, and METEOSAT 7.

(c) 3B42RT (Combination of HQ and VAR). This algorithm provides a combination of the TRMM real-time merged passive microwave (HQ, 3B40RT) and microwave-calibrated IR (VAR, 3B41RT). The current scheme is a simple replacement: for each grid box the HQ value is used if available, and otherwise the VAR value is used. The precipitation estimates 
are on a 3-hourly temporal resolution and a $0.25^{\circ} \times 0.25^{\circ}$ spatial resolution.

2.1.2. TRMM-3B43. The algorithm $3 \mathrm{~B} 43$ is applied to produce the "TRMM and Other Data" best-estimate precipitation rate and root-mean-square (RMS) precipitation-error estimates by combining the 3-hourly merged HQ/IR estimates with the monthly accumulated Global Precipitation Climatology Centre (GPCC) rain gauge analysis. These gridded estimates are on a calendar month temporal resolution and a $0.25^{\circ} \times 0.25^{\circ}$ spatial resolution.

The 3-hourly merged high-quality IR estimates are summed for the calendar month, and then a large-scale bias adjustment is applied to the multisatellite estimates by use of the rain gauge data, almost exclusively over land. The monthly gauge-adjusted merged satellite estimate is then combined directly with the rain gauge estimates using inverse error variance weighting [26]. This algorithm is very similar to and directly follows that developed for the GPCP's monthly satellite-gauge (SG) product $[28,29]$.

\subsection{GPCP Products}

2.2.1. GPCP V1.2 One-Degree Daily (1DD). The GPCP (Global Precipitation Climatology Project) 1DD uses the "best" quasi-global observational estimators of underlying statistics to adjust quasi-global observational datasets that have desirable time/space coverage. Specifically, SSMI and SSMIS calculated from GPROF algorithm provide fractional occurrence of precipitation. GPCP version 2.2 SG combination provides monthly accumulation of precipitation to algorithms applied to geo-IR $T_{b}$ histograms, low-orbit IR GOES precipitation index, and TOVS. Microwave precipitation estimates and gauge analyses are not explicitly used due to sampling limitations; however, the calibration of the 1DD to the monthly version 2.2 SG ensures that they do have a strong influence on the overall scaling. The grid precipitation field is presented at $1^{\circ} \times 1^{\circ}$ resolution. Details of the GPCP 1DD algorithm are given in Huffman et al. [30]. The GPCP V1.2 products are available from July 1997 to December 2014, so in our analysis its climatology is averaged from 1998 to 2014.

2.2.2. GPCP Version 2.2 Combined Precipitation. The GPCP version 2.2 has been developed for its long-term (1979present) global SG dataset to take advantage of the improved GPCC gauge analysis, which is a key input. The substantive changes relative to version 2.0 are the use of the new GPCC full data reanalysis (version 4) for 1979-2014 and the new GPCC monitoring product (version 2) thereafter and recalibration of the OLR precipitation index (OPI) data to a longer (20-year) record of the new SSM/I-era GPCP data. See Huffman et al. [31] for further details on the merging techniques.

2.3. CMAP Products. CMAP (CPC Merged Analysis of Precipitation) monthly precipitation data are available on the CPC website (http://www.esrl.noaa.gov/psd/data/gridded/ data.cmap.html). Two versions have been released: CMAP-1, which merges gauge observations, satellite observations, and the NCEP/NCAR reanalysis, and CMAP-2, which includes the same inputs except for reanalysis precipitation [32]. Both are in $2.5^{\circ} \times 2.5^{\circ}$ horizontal resolution covering the period from January 1979 through present. The merging technique of CMAP is described in detail by Xie and Arkin [32]. In this study, CMAP-2 monthly data from January 1979 to December 2014 are utilized.

2.4. Other Datasets. The dataset used to document the associated large-scale circulation is derived from the European Center for Medium-range Weather Forecasts (ECMWF) interim reanalysis (ERA-Interim) dataset (http:// data-portal.ecmwf.int/data/d/interim_daily/). ERA-Interim is an "interim" reanalysis from 1979 to the present in preparation for the next-generation extended reanalysis of reanalysis ERA-40. The former is more extensive than that for the latter; for example, the number of pressure levels is increased from ERA-40's 23 to 37 levels with additional cloud parameters included. ERA-Interim products are also publicly available on the ECMWF data server, at a $0.75^{\circ}$ by $0.75^{\circ}$ resolution, including several products that were not available for ERA-40. In our study, we use the ECWMF interim dataset covering the $\mathrm{BoB}$ in the 2002 and 2005 summer monsoon seasons.

In addition, the hourly MTSAT-IR (Multifunctional Transport Satellite) equivalent black body temperature (Tbb) data [33] (http://weather.is.kochi-u.ac.jp/archive-e.html) at $0.25^{\circ} \times 0.25^{\circ}$ resolution in the summers of 2002 and 2005 are also used as a proxy of convective cloud feature in our analysis.

\section{Results}

3.1. Climatology. Figure 1 shows the distributions of the summer (JJA) mean precipitation from TRMM 3B43 and GPCP V1.2 during 1998-2014, GPCP V2.2 and CMAP during 1979-2014, and the TRMM subproducts of 3B40RT, 3B41RT, and 3B42RT during 2000-2014. Different lengths of the datasets are chosen in order to obtain the climatology feature based on data as long as possible. All datasets except for CMAP show similar spatial pattern. The rain belt lies along the eastern coast in the northern $\mathrm{BoB}$ with the maximum precipitation center over the ocean offshore. The summer rainfall climatology of TRMM products with high spatial resolution of $0.25^{\circ} \times 0.25^{\circ}$ (Figures $1(\mathrm{a}), 1(\mathrm{e}), 1(\mathrm{f})$, and $1(\mathrm{~g})$ ) shows clearly the rain shadow on the leeward side associated with the orographic effect of Araka Yoma. Moreover, the rainfall maximum is not located on the windward slope of the mountain range but instead is offshore by as much as $200 \mathrm{~km}$ from the eastern coast (Figures $1(\mathrm{a}), 1(\mathrm{e}), 1(\mathrm{f})$, and $1(\mathrm{~g})$ ). The GPCP products (Figures 1(b) and 1(c)) agree well with TRMM products on relatively broad scales but differ in details. The precipitation amounts in GPCP V1.2 and V2.2 are smaller on windward side while being greater on leeward side than those in the TRMM 3B43 and 3B42RT, suggesting an overall weaker lifting effect of the narrow mountain in the GPCP products. Note that overall both TRMM 3B40RT and 3B41RT (Figures $1(\mathrm{e})$ and $1(\mathrm{f})$ ) show lower precipitation amounts than TRMM 


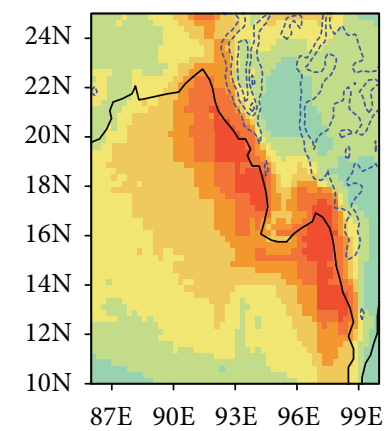

(a) TRMM 3B43

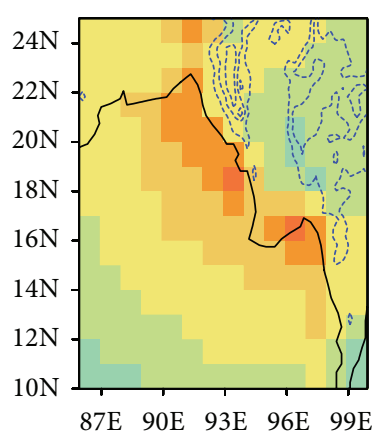

(b) GPCP V1.2

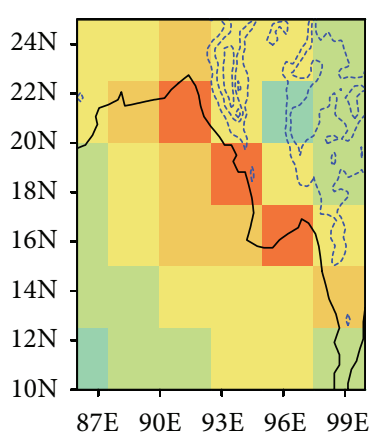

(c) GPCP V2.2

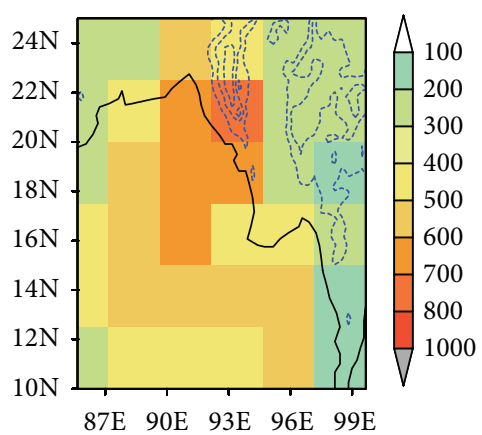

(d) CMAP

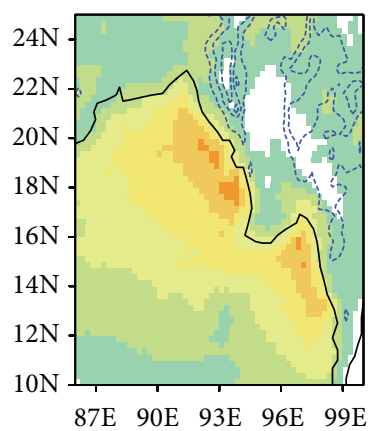

(e) TRMM 3B40RT

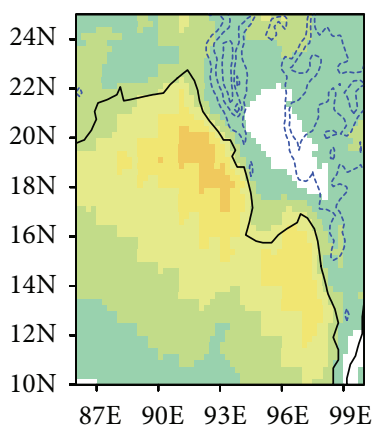

(f) TRMM 3B41RT

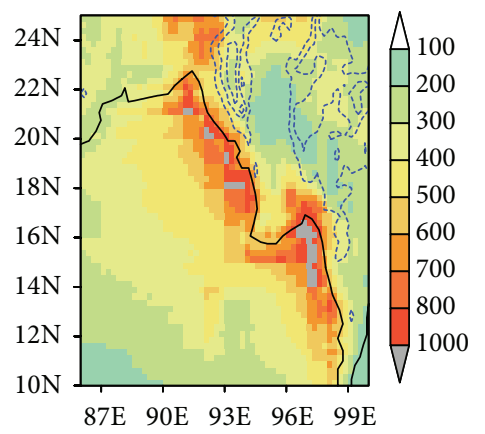

(g) TRMM 3B42RT

FIGURE 1: Distribution of climatological JJA mean precipitation ( $\mathrm{mm}$ month $^{-1}$ ) of the TRMM 3B43 and GCPC V1.2 from 1998 to 2014 , GPCP V2.2 and CMAP products from 1979 to 2014, and TRMM 3B40RT, 3B41RT, and 3B42RT products from 2000 to 2014. The blue dotted contours mark the topography at $500 \mathrm{~m}, 1000 \mathrm{~m}$, and $1500 \mathrm{~m}$ above the sea level.

3B43 and 3B42RT (Figures 1(e) and 1(g)). TRMM 3B41RT (Figure 1(f)) seems to show too low precipitation amount compared to other TRMM precipitation products while it gives similar spatial rainfall distribution in the region.

In sharp contrast, the orographic rainfall is poorly represented in the CMAP products (Figure 1(d)). An east-west orientated rain belt is found with the center located over the top of the terrain and its east. This difference between CMAP and other datasets seems to be not because of the coarse resolution since similar features can be found in GPCP V2.2 product (Figure $1(\mathrm{c})$ ), which has a horizontal resolution of $2.5^{\circ} \times 2.5^{\circ}$, the same as the CMAP product. Therefore, different location in the precipitation maximum in CMAP may require a different explanation as suggested by Xie et al. [14].

Consistency can also be found among all TRMM and GPCP products for the climatological precipitation seasonal variation in JJA averaged in the latitudinal band between $19^{\circ} \mathrm{N}$ and $21^{\circ} \mathrm{N}$ shown in Figure 2. The rain increases with time and reaches the peak in June and July. Note that TRMM 3B43, GPCP V2.2, and CMAP are monthly mean precipitation data while the other four products are daily data. A rainband appears in the longitude range between $90^{\circ} \mathrm{E}$ and $93^{\circ} \mathrm{E}$, on the windward side of the terrain, while significant rain shadow appears on the leeward side. All four daily precipitation products show very similar temporal evolution. In CMAP (Figure 2(d)), the rainband shifts eastward to $93^{\circ}-$ $96^{\circ} \mathrm{E}$, again suggesting its poor performance in depicting the orography effect on local scale precipitation. Therefore, the CMAP product will not be considered in the comparison of interannual variability below.

3.2. Interannual Variability. Precipitation in the Asian monsoon region displays large interannual variability. In order to compare the ability of different products in depicting the interannual variation of precipitation in this region, two cases, that is, JJA of 2002 and 2005, are chosen. As shown in Figure 3(a), in JJA of 2002, the rainband from TRMM 3B43 lies along the shore with a well-defined maximum near the eastern coast. By contrast, the center of rainfall maximum was displaced to the open ocean in JJA of 2005 (Figure 3(g)). Indeed, the distribution of precipitation in JJA averaged between $19^{\circ}$ and $21^{\circ} \mathrm{N}$ (Figure 4(a)) also reveals the difference between 2002 and 2005 associated with the orographic effect of Araka Yoma. The precipitation maximum in 2002 was located east at $93^{\circ} \mathrm{E}$, while in 2005 two centers were located, respectively, at $92^{\circ} \mathrm{E}$ and $91.5^{\circ} \mathrm{E}$, about $100-$ $200 \mathrm{~km}$ more offshore. Moreover, the associated maximum in rain rate in 2005 was about $920 \mathrm{~mm} \mathrm{month}^{-1}$, less than that in $2002\left(952.5 \mathrm{~mm} \mathrm{month}^{-1}\right)$. Therefore, the rain rate derived from TRMM 3B43 product exhibits significant interannual variation in both location and magnitude, with more offshore located rainfall maximum and weaker rainfall amount in 2005 than that in 2002. This is the main reason why the JJA of 2002 and the JJA of 2005 are chosen to investigate the interannual variability in this study. Similar features can 


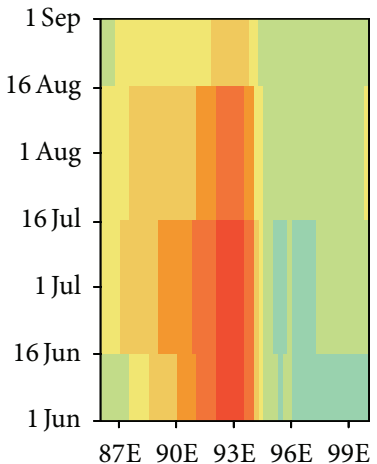

(a) TRMM 3 B 43

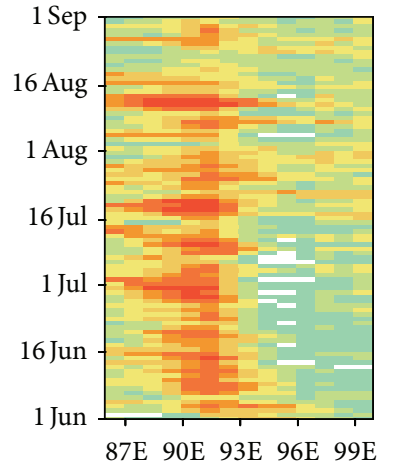

(b) GPCP V1.2

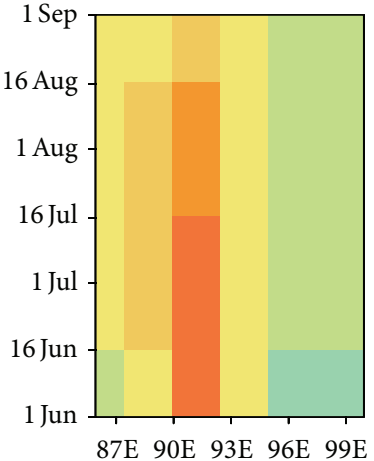

(c) GPCP V2.2

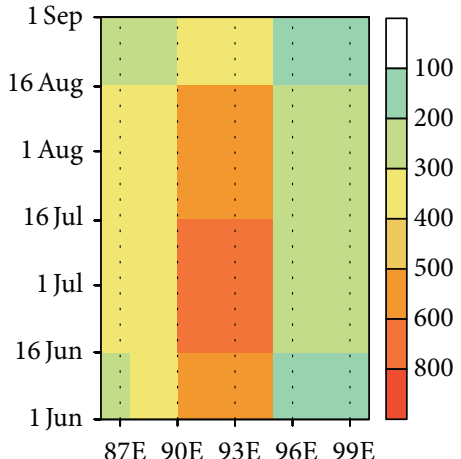

(d) CMAP

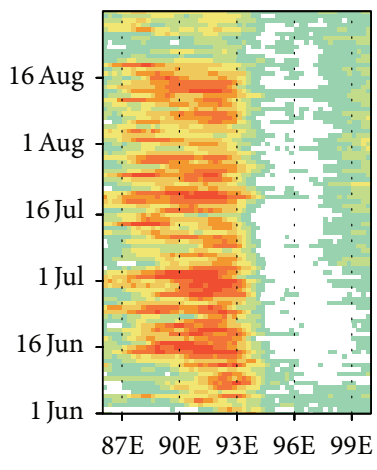

(e) TRMM 3B40RT

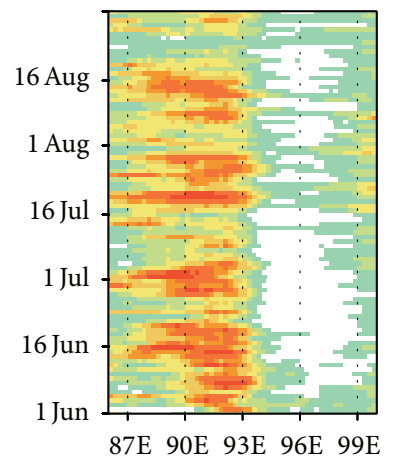

(f) TRMM 3B41RT

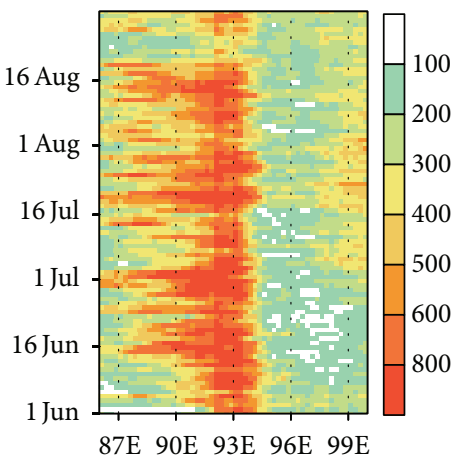

(g) TRMM 3B42RT

FIGURE 2: Climatological mean seasonal evolution of precipitation $\left(\mathrm{mm} \mathrm{month}{ }^{-1}\right)$ in JJA averaged in the latitudinal band of $19^{\circ}-21^{\circ} \mathrm{N}$ from various precipitation products as indicated in each panel.

be found in precipitation products GPCP V1.2 and TRMM 3B41RT (Figures 3 and 4 and Table 1).

TRMM 3B40RT product agrees well with TRMM 3B43 in the rain maximum distribution. The rainfall center shifts westward to the open ocean in JJA 2005 relative to that in 2002 (Figures 3(d) and 3(j)). Although it shows the distance of only about $100 \mathrm{~km}$ between the rain centers in 2002 and 2005 (Figure 4(d)), TRMM 3B40RT still clearly depicts remarkable interannual variability of the offshore precipitation in the studied region. Significant discrepancy between TRMM 3B40RT and 3B43 lies in the rainfall intensity. As shown in Figure 4(d), along the latitudinal band of the mesoscale mountain $\left(19^{\circ}-21^{\circ} \mathrm{N}\right)$, the maximum of the averaged precipitation in 2005 reaches as large as $750 \mathrm{~mm} \mathrm{month}^{-1}$, while that in 2002 is less than $600 \mathrm{~mm} \mathrm{month}^{-1}$. Moreover, the rainfall amount near shore in 2005 is also larger by $50 \mathrm{~mm} \mathrm{month}^{-1}$ than that in 2002 (Table 1).

However, the GPCP V2.2 shows the precipitation maximum at the same position in 2002 and 2005 (Figures 3(c), 3(i), and 4(c)). The precipitation intensity in JJA 2002 and 2005 is also very similar (Figure 4(c) and Table 1). These suggest that the GPCP V2.2 produces little interannual variation of both the location of precipitation center and rainfall intensity. Similarly, TRMM 3B42RT product also gives the rainband centered near the shore in JJA in both 2002 and 2005 (Figures $3(\mathrm{f}), 3(\mathrm{l})$, and $4(\mathrm{f}))$. The only difference from GPCP V2.2 is
TABLE 1: The precipitation amount $\left(\mathrm{mm} \mathrm{month} \mathrm{h}^{-1}\right)$ over $92^{\circ}-93^{\circ} \mathrm{E}$, $19^{\circ}-21^{\circ} \mathrm{N}$ in JJA of 2002 and 2005.

\begin{tabular}{lcc}
\hline Precipitation products & 2002 JJA & 2005 JJA \\
\hline TRMM 3B43 & 907.6 & 899.9 \\
GPCP V1.2 & 579.7 & 561.7 \\
GPCP V2.2 & 537.4 & 516.8 \\
TRMM 3B40RT & 499.1 & 551.2 \\
TRMM 3B41RT & 463.9 & 435.3 \\
TRMM 3B42RT & 777.5 & 853.7 \\
\hline
\end{tabular}

that the rainfall amount is a little bit larger in 2005 than in 2002 in TRMM 3B42RT (Figure 4(f) and Table 1).

Both the spatial rainfall distribution and rainfall intensity (Figures 3 and 4 and Table 1 ) suggest that the TRMM products (except for 3B42RT) and GPCP V1.2 present significant interannual variability over the east $\mathrm{BoB}$ in terms of the offshore precipitation distribution forced by the mesoscale mountain (Araka Yoma) in summer monsoon season, as demonstrated for 2002 and 2005. The rainfall maximum is located more offshore in JJA in 2005 than in 2002. For precipitation intensity, only TRMM 3B40RT and 3B42RT display larger rainfall amount in JJA in 2005 than in 2002 in both oceanic and coastal regions. In sharp contrast, 


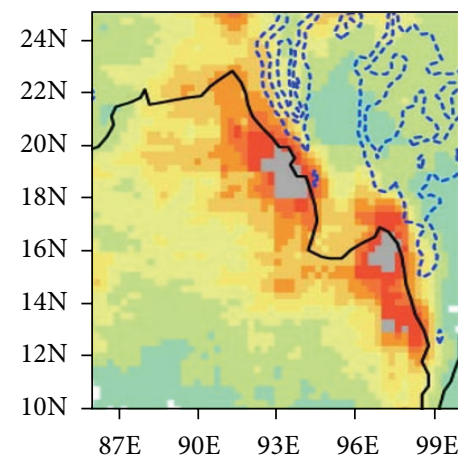

(a) 3B43 2002

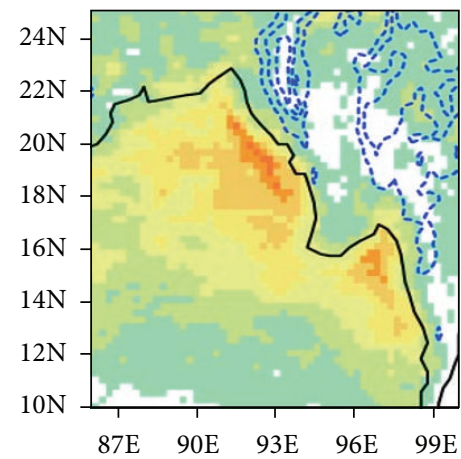

(d) 3B40RT 2002

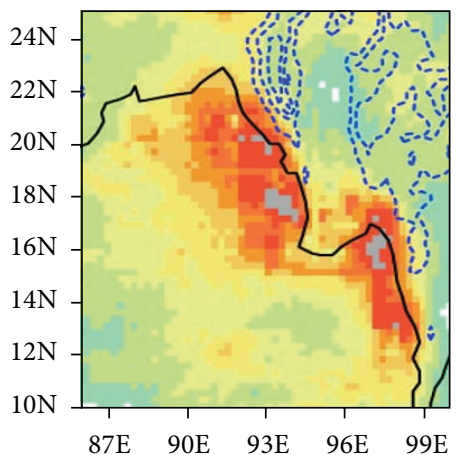

(g) 3B43 2005

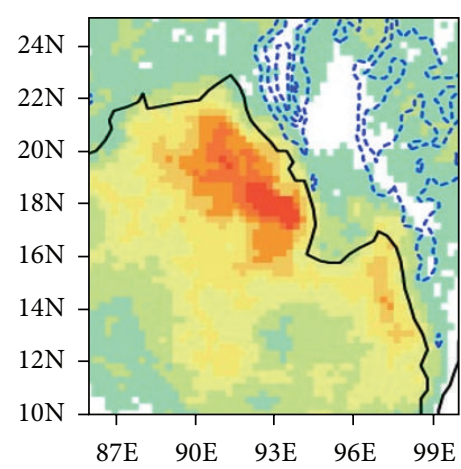

(j) 3B40RT 2005

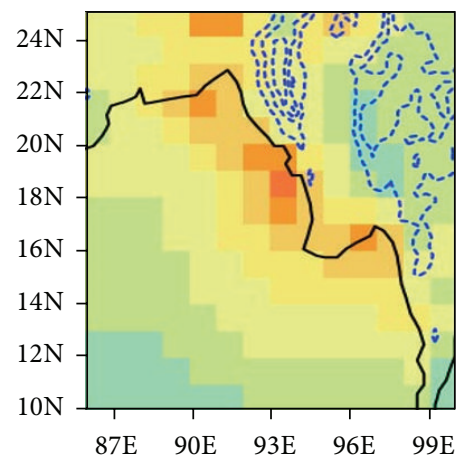

(b) GPCP V1 2002

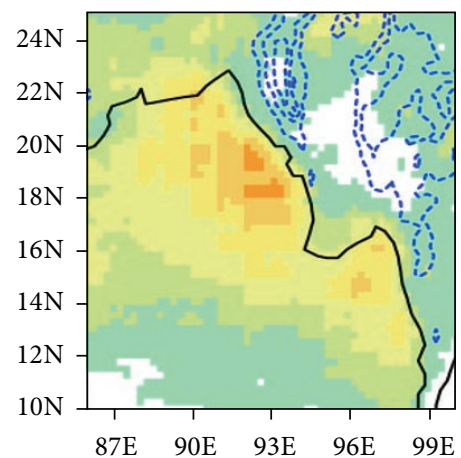

(e) 3B41RT 2002

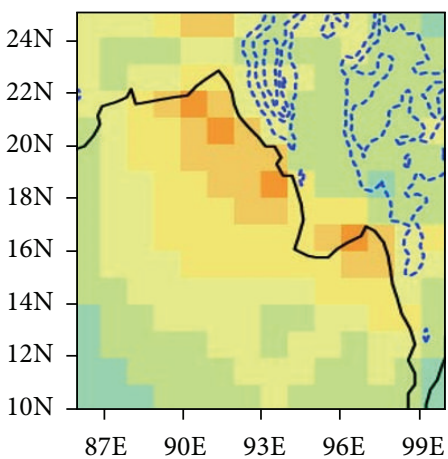

(h) GPCP V1 2005

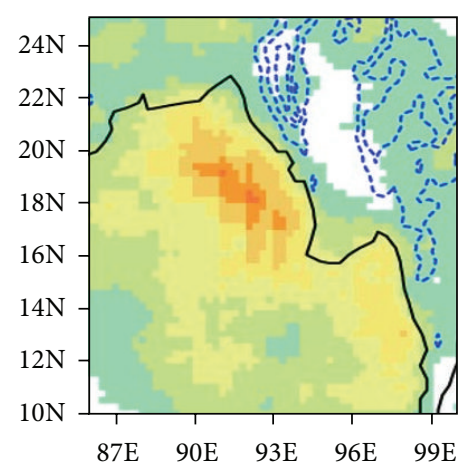

(k) 3B41RT 2005

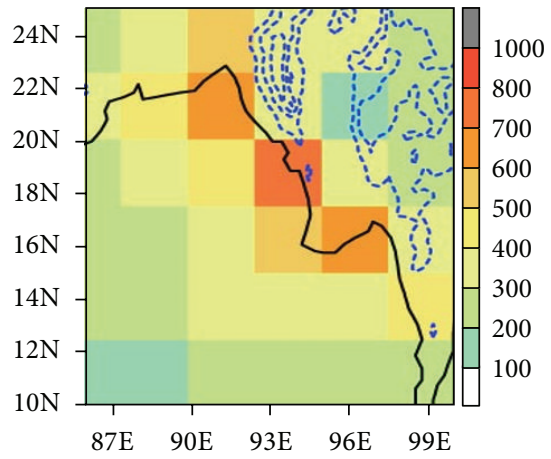

(c) GPCP V2 2002

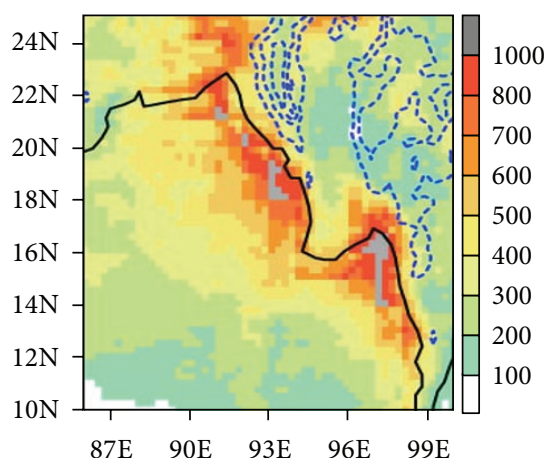

(f) 3B42RT 2002

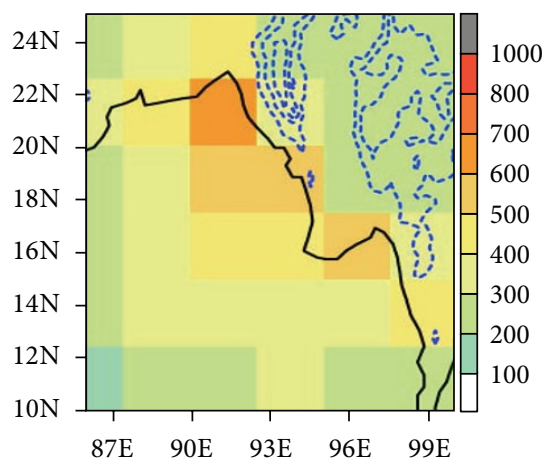

(i) GPCP V2 2005

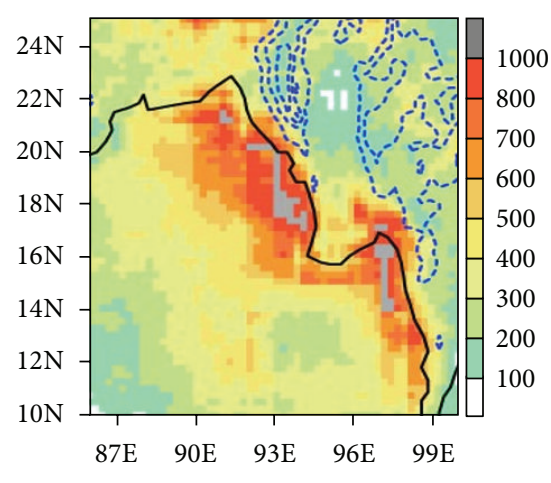

(l) 3B42RT 2005

FIGURE 3: JJA mean precipitation (mm month $\left.{ }^{-1}\right)$ distribution in $2002((\mathrm{a})-(\mathrm{f}))$ and 2005 ((g)-(l)). The blue dotted contours mark the topography at $500 \mathrm{~m}, 1000 \mathrm{~m}$, and $1500 \mathrm{~m}$ above sea level. 


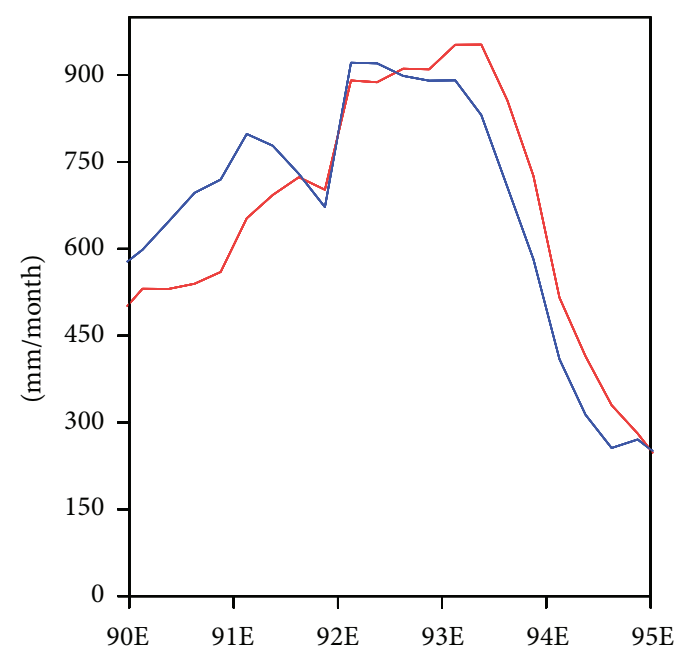

(a) $3 \mathrm{~B} 43$

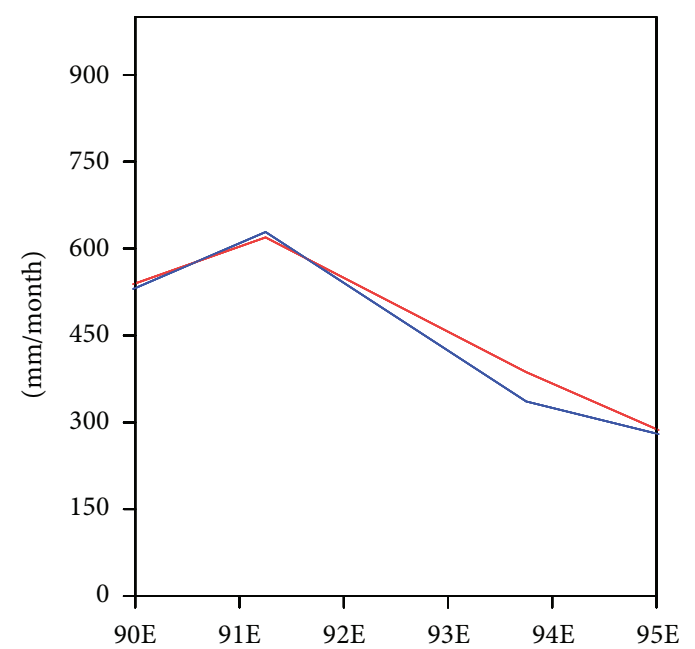

(c) GPCP V2

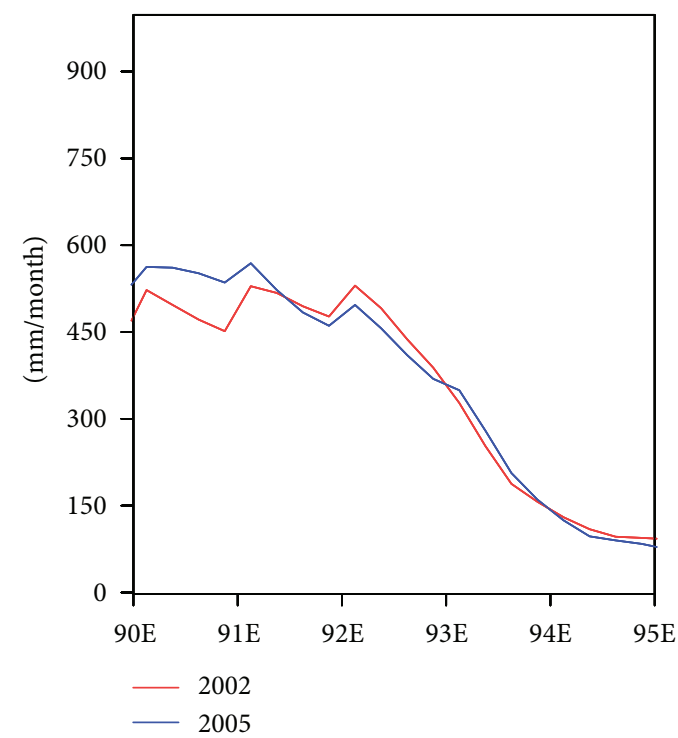

(e) 3B41RT

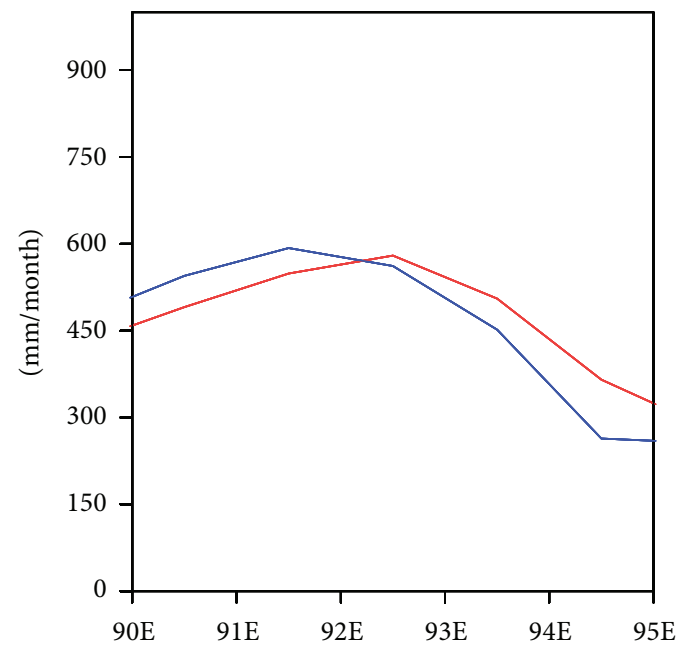

(b) GPCP V1

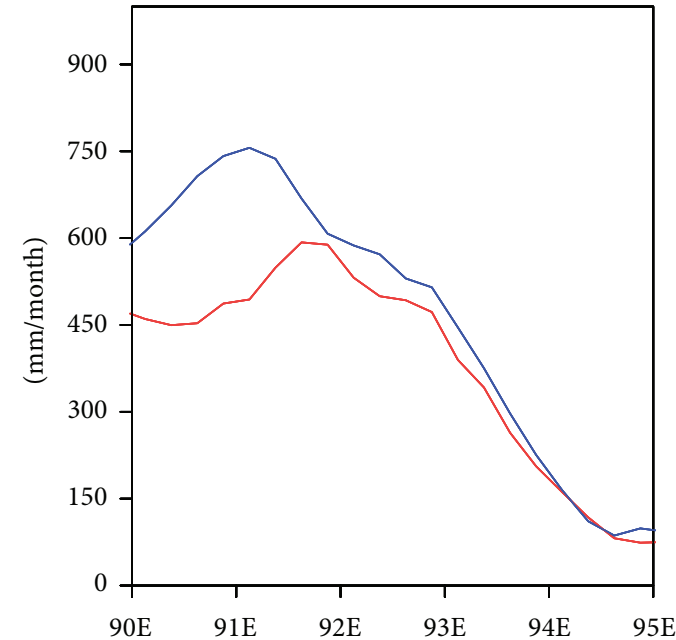

(d) $3 \mathrm{~B} 40 \mathrm{RT}$

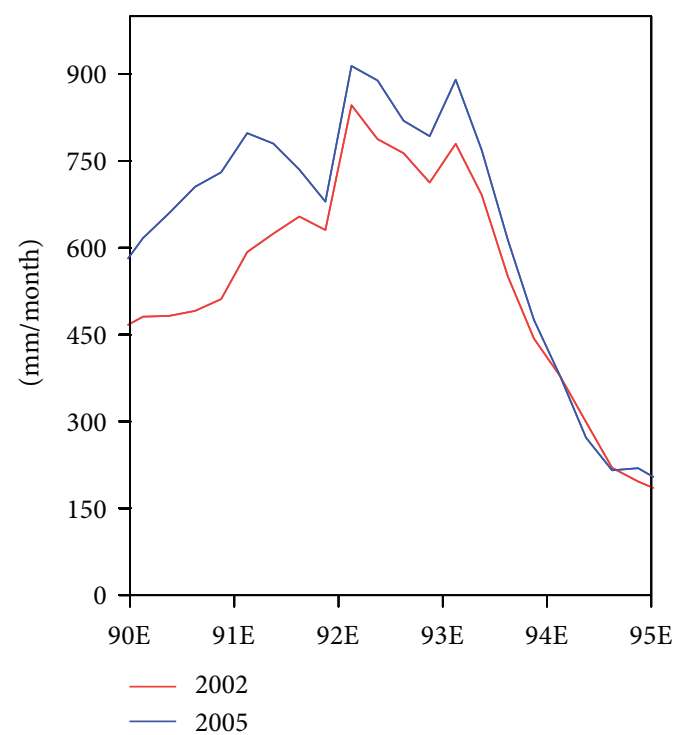

(f) $3 \mathrm{~B} 42 \mathrm{RT}$

FIGURE 4: JJA mean precipitation $\left(\mathrm{mm} \mathrm{month}^{-1}\right)$ averaged within latitudinal band of $19-21^{\circ} \mathrm{N}$ in 2002 and 2005. 


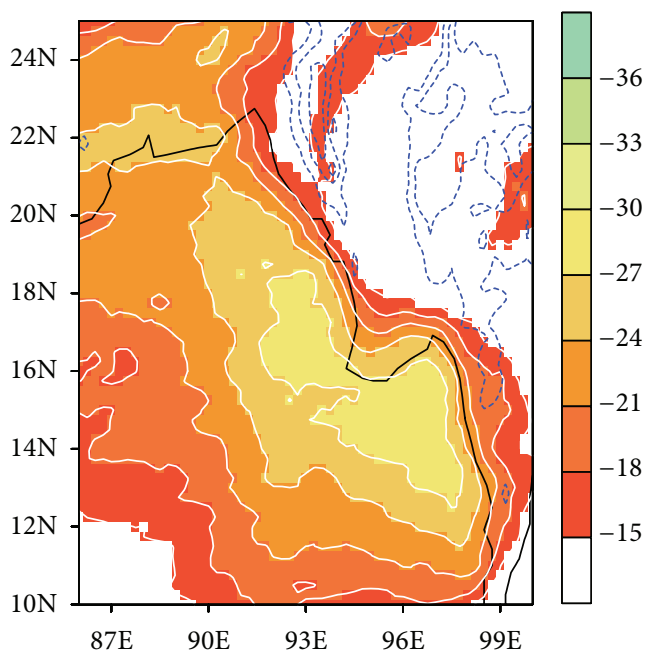

(a) 2002JJA

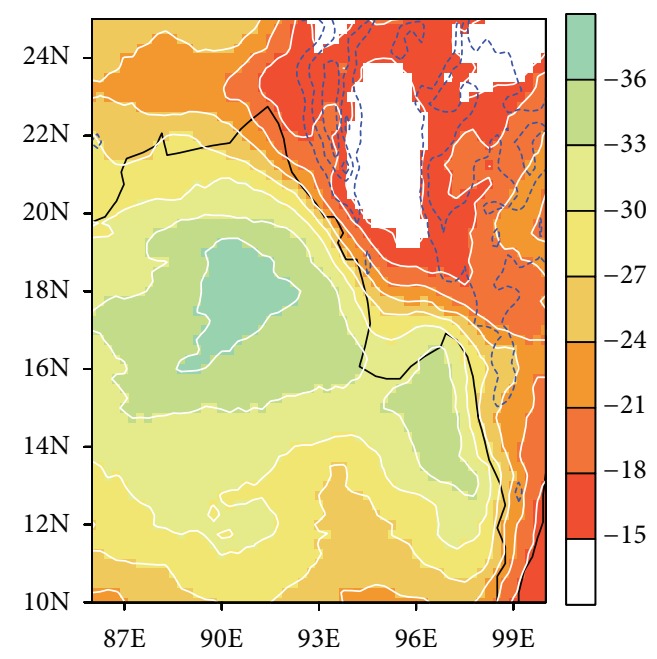

(b) 2005JJA

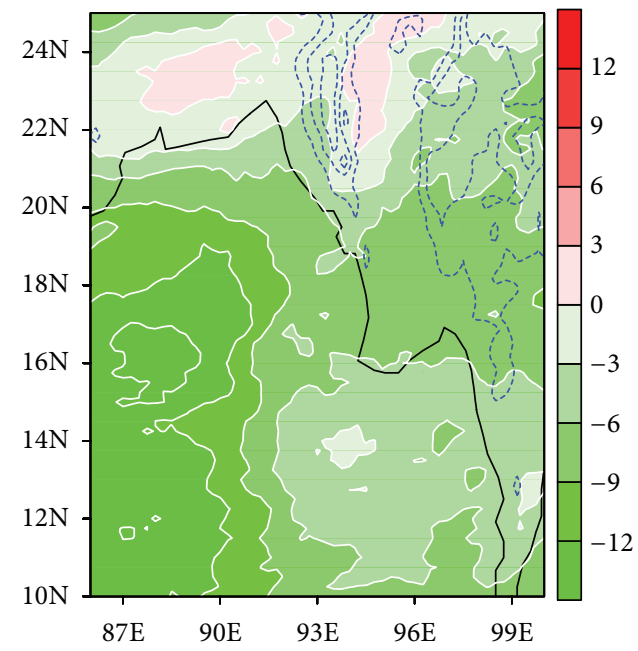

(c) 2005-2002

FIGURE 5: JJA mean black body temperature ( $\mathrm{Tbb}^{\circ}{ }^{\circ} \mathrm{C}$ ) distribution in 2002 (a), 2005 (b), and their difference (c). The purple dotted contours are the topography at $500 \mathrm{~m}, 1000 \mathrm{~m}$, and $1500 \mathrm{~m}$ above sea level.

GPCP V2.2 and TRMM 3B42RT products show little yearto-year variation. This suggests, as summarized in Table 2, that obvious discrepancy exists among different precipitation products in the east BoB, not only in the spatial precipitation distribution, but also in the rainfall intensity.

A question rises as to which precipitation product is more reliable over the east BoB in the summer monsoon season in terms of the offshore precipitation maximum feature. To answer this question, we analyzed the satellite Tbb data for a comparison. Figure 5 shows a close examination of Tbb from MTSAT, which indicates that the convection center in 2005 shifts westward to the open ocean relative to that in 2002 . The lowest $\mathrm{Tbb}$ value is below $-36^{\circ} \mathrm{C}$ in 2005 , suggesting more intense convection in 2005 than in 2002. The Tbb is colder in JJA 2005 than in JJA 2002 not only in the open ocean but also in the coastal regions (Figure 5(c)), suggesting that there should be more convective precipitation over the coastal region in 2005. Among different precipitation products, the rainfall distribution from TRMM 3B40RT largely follows that inferred from the Tbb activity, with the larger precipitation both near shore and offshore in 2005 than in 2002.

Furthermore, previous modeling studies based on short $(\sim 1$ day) integrations indicate that the observed displacement of the rainfall maximum away from the mountain summit is sensitive to the vertical shear of the prevailing winds and latent and sensible heat fluxes from the ocean [34]. During the focused period of this study, the low-level flow was characterized by the fully developed monsoon westerlies over the $\mathrm{BoB}$, and the upper levels were prevailed by tropical easterlies, giving rise to the prevailing strong easterly shear.

Figure 6 compares the vertical profiles of zonal wind and vertical motion averaged between $19^{\circ}$ and $21^{\circ} \mathrm{N}$ in JJA of 2002 and 2005. General features are similar to each other, with easterly vertical shear in both 2002 and 2005 and zero zonal wind at about $500 \mathrm{hPa}$ (Figures 5(a) and 5(b)). However, the zonal wind in the lower levels in the westerly 


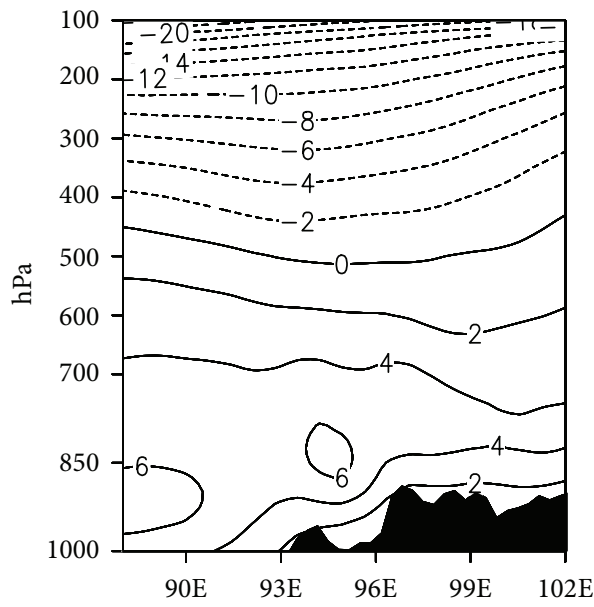

(a) U 2002JJA

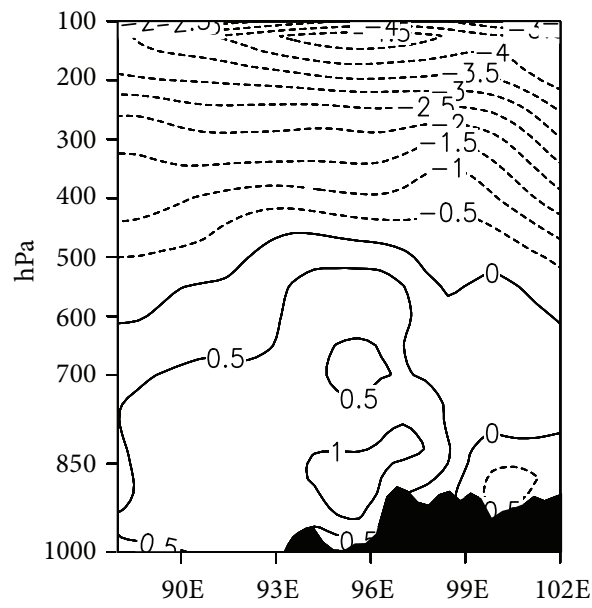

(c) U 2005-2002

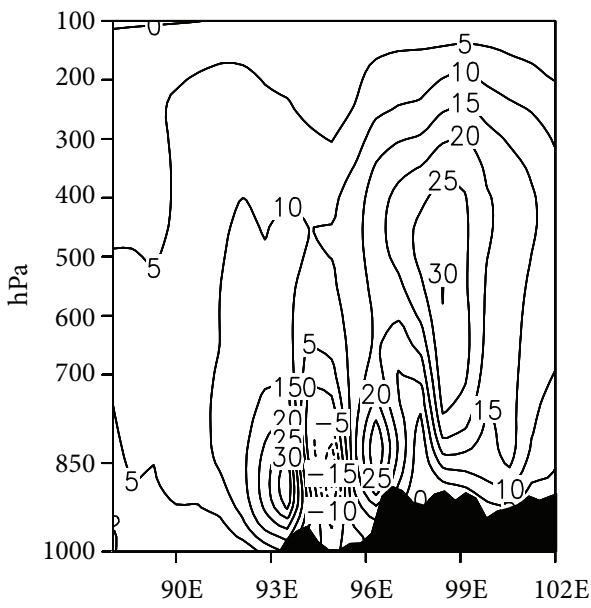

(e) W 2005JJA

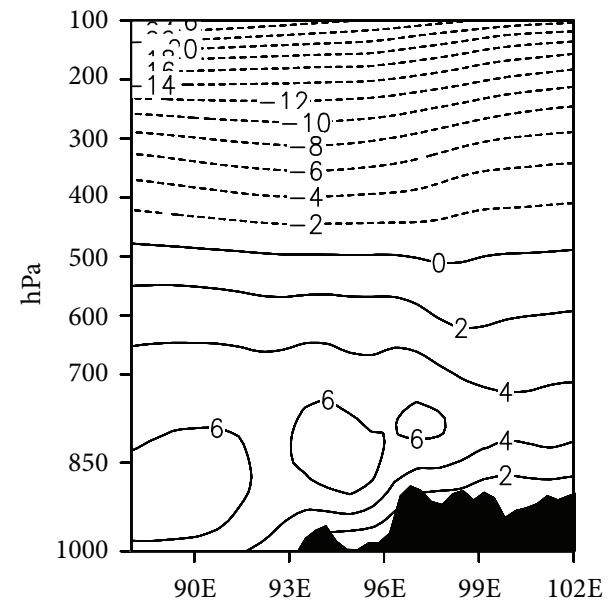

(b) U 2005JJA

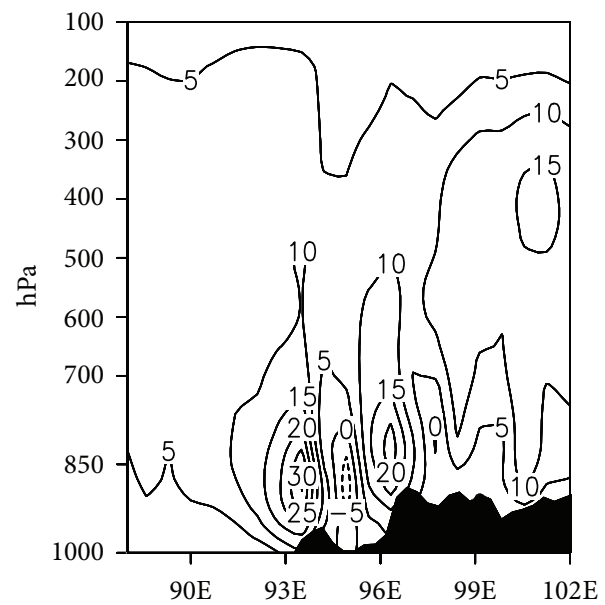

(d) W 2002JJA

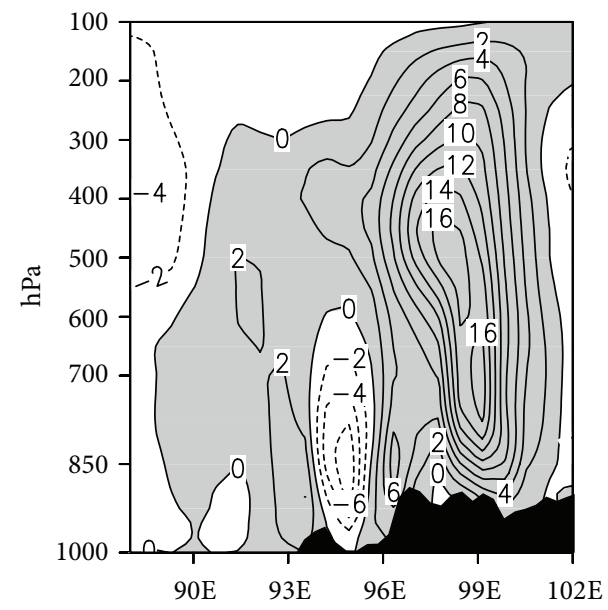

(f) W 2005-2002

FIGURE 6: JJA mean zonal wind $\left(\mathrm{m} \mathrm{s}^{-1}\right)$ and vertical motion $\left(-1.0 \times 10^{-2} \mathrm{~Pa} \mathrm{~s}^{-1}\right)$ from the ECMWF ERA-Interim data at $0.75^{\circ}$ resolution in 2002 ((a), (d)), 2005 ((b), (e)), and their difference ((c), (f)) averaged within latitudinal band of $19-21^{\circ} \mathrm{N}$. 


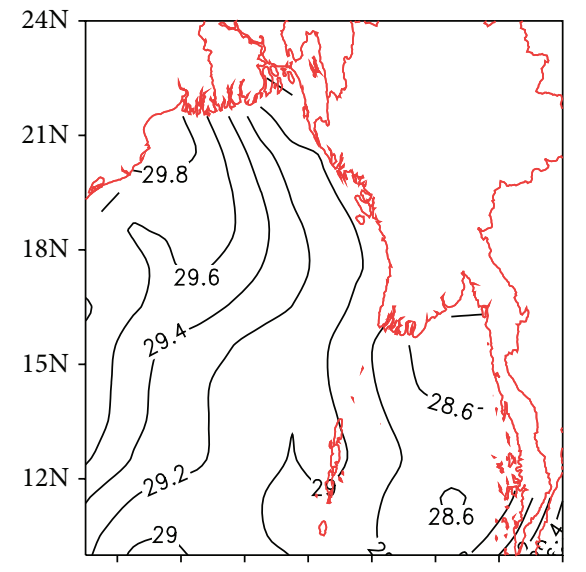

$86 \mathrm{E} \quad 88 \mathrm{E} \quad 90 \mathrm{E} \quad 92 \mathrm{E} \quad 94 \mathrm{E} \quad 96 \mathrm{E} \quad 98 \mathrm{E} \quad 100 \mathrm{E}$

(a) 2002JJA

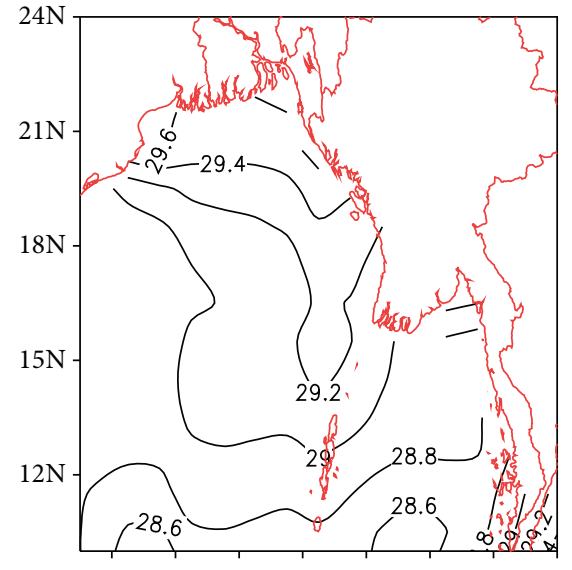

$86 \mathrm{E} \quad 88 \mathrm{E} \quad 90 \mathrm{E} \quad 92 \mathrm{E} \quad 94 \mathrm{E} \quad 96 \mathrm{E} \quad 98 \mathrm{E} \quad 100 \mathrm{E}$

(b) 2005JJA

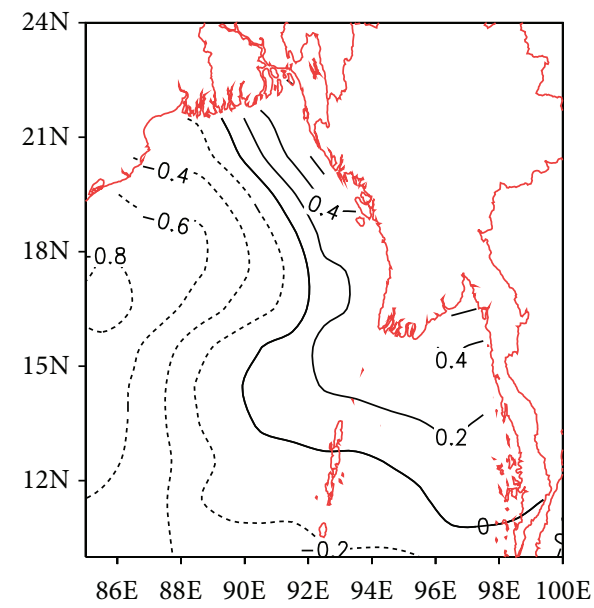

(c) 2005-2002

FIGURE 7: JJA mean sea surface temperature (SST in ${ }^{\circ} \mathrm{C}$ ) derived from OISST data in 2002 (a), 2005 (b), and their difference (c).

TABLE 2: Summary of the precipitation products in representing the differences in the offshore rainfall maximum and intensity in the east BoB between 2002 JJA and 2005 JJA.

\begin{tabular}{lcc}
\hline Precipitation products & More offshore located rainfall maximum in 2005 & Greater rainfall intensity in 2005 near shore \\
\hline TRMM 3B43 & Yes & No \\
GPCP V1.2 & Yes & No \\
GPCP V2.2 & No & No \\
TRMM 3B40RT & Yes & Yes \\
TRMM 3B41RT & Yes & No \\
TRMM 3B42RT & No & Yes \\
\hline
\end{tabular}

phase is stronger in 2005 than in 2002 (Figure 6(c)). In the upper levels the easterly in 2005 is about $4 \mathrm{~m} \mathrm{~s}^{-1}$ stronger than that in 2002 (Figure 6(c)). Although the orographic lifting on the windward side did occur in both 2002 and 2005 , its intensity was weaker in the former year than in the latter, consistent with the weaker low-level prevailing wind. The weaker upward motion also extended over the near shore ocean in the east $\mathrm{BoB}$, showing the vertical $p$ velocity about $2 \times 10^{-2} \mathrm{~Pa} \mathrm{~s}^{-1}$ weaker over the coastal ocean in 2002 than in 2005 (Figure 6(f)). Furthermore, the sea surface temperature (SST) over the east $\mathrm{BoB}$ was over $0.4^{\circ} \mathrm{C}$ warmer in 2005 than in 2002 (Figure 7(c)), implying more favorable thermodynamic conditions for convection to occur in 2005. Thus, larger rainfall would be induced near shore in 2005. Based on the simulation results of [34], deep convection tends to develop offshore when the SST is higher and the low-level winds are stronger in 2005 because both tend to enhance surface heat and moisture fluxes. Therefore, the more 
westward located offshore rainfall maximum with larger amplitude is expected in the 2005 monsoon season than in 2002 because of the stronger easterly vertical shear and larger surface heat and moisture fluxes associated with the warmer ocean surface and stronger low-level (surface) winds.

\section{Concluding Remarks}

In this study, we have compared several commonly used precipitation products to examine their strength in representing the precipitation features during the fully developed Asian summer monsoon season in the east BoB. The outstanding features of the monsoon rainfall in this area lie not only in its large precipitation amount, but also in its geographical distribution. The rainfall maximum is northwest-southeast-oriented, along the eastern coast of the $\mathrm{BoB}$ and on the windward side of the mountain summit. In climatology, all precipitation products present similar distribution of rainfall distribution except for the CMAP. However, significant discrepancies are found among different precipitation products in the year-to-year variation in both precipitation distribution and intensity, as illustrated by contrasting the summer rainfall in 2002 and 2005. Based on the TRMM products (except for 3B42RT) and GPCP V1.2, the precipitation maximum was located near the coast in JJA of 2002 while being about $100-200 \mathrm{~km}$ offshore over the open sea in 2005. However, the rainfall distribution derived from GPCP V2.2 product and TRMM 3B42RT shows little difference between 2002 and 2005 summers, with near shore rainfall maximum. For the rainfall intensity, only TRMM 3B40RT and 3B42RT show larger rainfall amount in both the oceanic and coastal regions in JJA 2005 than that in JJA 2002.

The distribution of Tbb also suggests more active convection in 2005 not only in open ocean but also near shore than in 2002 (Figure 5(c)). Furthermore, the large-scale circulation and SST fields in 2002 and 2005 were compared to infer the dynamical and thermodynamic forcings potentially contributing to the difference in the rainfall distribution between the two summers. The results show that greater large-scale easterly vertical wind shear and higher SST over the east BoB occurred in 2005 than in 2002. This leads to more offshore rainfall maximum with larger rainfall intensity in 2005, a distinct feature that is well captured by the TRMM 3B40RT precipitation products. In sharp contrast, the relatively weaker easterly vertical wind shear and lower SST over the east $\mathrm{BoB}$ in 2002 were less favorable for the offshore propagation of orographically forced convection, resulting in the rainfall maximum of lower amount near the coastline. The difference between 2002 and 2005 infers the remarkable interannual variation in the offshore rain distribution and intensity in the coastal region of the east BoB. The results suggest that the TRMM 3B40RT products are more reliable among different precipitation products examined in this study in terms of the offshore precipitation distribution and intensity in the coastal region of the east BoB.
Comparing the algorithms of these precipitation products, only the TRMM 3B40RT is primarily based on the passive microwave, while others are from IR estimation (TRMM 3B41RT) or the combination of passive microwave and IR estimations (TRMM 3B42RT, TRMM 3B43, and GPCP products). The discrepancies of these precipitation products in representing the offshore precipitation features in the east BoB may imply that the passive microwave-based precipitation is more reliable in the east $\mathrm{BoB}$ than the IR estimated rainfall.

Note that the interannual variability of the offshore rainfall distribution in the eastern $\mathrm{BoB}$ is inferred from the contrasts between two summer monsoon seasons (2002 and 2005). Although a complete comparison through the whole analysis period (1998-2014) could be done, we found that 17 years are still too short for a statistical analysis for the interannual variability. Nevertheless, the two typical years we chose provide the insight into the physical processes behind the difference in the rainfall distribution in the two years.

In addition, the widely used CMAP data fails to detect the orographically forced rainfall along the eastern coast of the BoB. The rainfall center in the CMAP appears over the peak of the Araka Yoma both in the climatology and in any particular year. Its failure could not be explained by its coarse resolution since GPCP V2.2 with the same resolution of $2.5^{\circ} \times 2.5^{\circ}$ gives comparable results as those from the higher resolution TRMM precipitation products. This indicates that the CMAP data have lower skill in capturing the orographically forced rainfall distribution associated with the mesoscale mountains in the studied region. Therefore, special attention should be given to the reliability and quality of the various precipitation datasets when regional and mesoscale features of precipitation in regions with orographic effects are a major concern.

\section{Conflict of Interests}

The authors declare that there is no conflict of interests regarding the publication of this paper.

\section{Acknowledgments}

This study has been supported by the National Key Technology R\&D Program of China with Grant no. 2012BAC22B03, the PICSC/USGS Grant G12AC20501 awarded to the University of Hawaii at Manoa, a project funded by the Priority Academic Program Development of Jiangsu Higher Education Institutions (PAPD), and Qing Lan Project. The data for this paper are available at http://precip .gsfc.nasa.gov/, http://www.esrl.noaa.gov/psd/data/gridded/ data.cmap.html, ftp://disc2.nascom.nasa.gov/data/TRMM/ Gridded/,http://data-portal.ecmwf.int/data/d/interim_daily/, and http://weather.is.kochi-u.ac.jp/archive-e.html. 


\section{References}

[1] R. F. Adler, G. J. Huffman, D. T. Bolvin, S. Curtis, and E. J. Nelkin, "Tropical rainfall distributions determined using TRMM combined with other satellite and rain gauge information," Journal of Applied Meteorology, vol. 39, no. 12, pp. 20072023, 2000.

[2] B. M. Fekete, C. J. Vörösmarty, J. O. Roads, and C. J. Willmott, "Uncertainties in precipitation and their impacts on runoff estimates," Journal of Climate, vol. 17, no. 2, pp. 294-304, 2004.

[3] G. Mahe, S. Girard, M. New et al., "Comparing available rainfall gridded datasets for West Africa and the impact on rainfallrunoff modelling results, the case of Burkina-Faso," Water $S A$, vol. 34, no. 5, pp. 529-536, 2008.

[4] H. K. Cho and H. Y. Chun, "Impacts on the TRMM data due to orbit boost in the spectral domain," Geophysical Research Letters, vol. 35, no. 1, Article ID L01403, 2008.

[5] K. P. Bowman, C. R. Homeyer, and D. G. Stone, "A comparison of oceanic precipitation estimates in the tropics and subtropics," Journal of Applied Meteorology and Climatology, vol. 48, no. 7, pp. 1335-1344, 2009.

[6] F. J. Turk, P. Arkin, E. E. Ebert, and M. R. P. Sapiano, "Evaluating high-resolution precipitation products," Bulletin of the American Meteorological Society, vol. 89, no. 12, pp. 1911-1916, 2008.

[7] L. E. O. C. Aragão, Y. Malhi, R. M. Roman-Cuesta, S. Saatchi, L. O. Anderson, and Y. E. Shimabukuro, "Spatial patterns and fire response of recent Amazonian droughts," Geophysical Research Letters, vol. 34, no. 7, 2007.

[8] Y. Liu, R. A. M. de Jeu, A. I. J. M. van Dijk, and M. Owe, "TRMM-TMI satellite observed soil moisture and vegetation density (1998-2005) show strong connection with El Niño in eastern Australia," Geophysical Research Letters, vol. 34, no. 15, Article ID L15401, 2007.

[9] J. Rhee, J. Im, and G. J. Carbone, "Monitoring agricultural drought for arid and humid regions using multi-sensor remote sensing data," Remote Sensing of Environment, vol. 114, no. 12, pp. 2875-2887, 2010.

[10] T. F. Lee, F. J. Turk, J. Hawkins, and K. Richardson, "Interpretation of TRMM TMI images of tropical cyclones," Earth Interactions, vol. 6, pp. 1-17, 2002.

[11] M. Lonfat, F. D. Marks Jr., and S. S. Chen, "Precipitation distribution in tropical cyclones using the Tropical Rainfall Measuring Mission (TRMM) microwave imager: a global perspective," Monthly Weather Review, vol. 132, no. 7, pp. 16451660, 2004.

[12] S. S. Chen, J. A. Knaff, and F. D. Marks Jr., "Effects of vertical wind shear and storm motion on tropical cyclone rainfall asymmetries deduced from TRMM," Monthly Weather Review, vol. 134, no. 11, pp. 3190-3208, 2006.

[13] W. A. Petersen and S. A. Rutledge, "Regional variability in tropical convection: observations from TRMM," Journal of Climate, vol. 14, no. 17, pp. 3566-3586, 2001.

[14] S.-P. Xie, H. Xu, N. H. Saji, Y. Wang, and W. T. Liu, "Role of narrow mountains in large-scale organization of Asian Monsoon convection," Journal of Climate, vol. 19, no. 14, pp. 3420-3429, 2006.

[15] L. Zhou and Y. Wang, "Tropical rainfall measuring mission observation and regional model study of precipitation diurnal cycle in the New Guinean region," Journal of Geophysical Research D: Atmospheres, vol. 111, no. 17, Article ID D17104, 2006.
[16] M. N. Islam and H. Uyeda, "Use of TRMM in determining the climatic characteristics of rainfall over Bangladesh," Remote Sensing of Environment, vol. 108, no. 3, pp. 264-276, 2007.

[17] R. Chokngamwong and L. S. Chiu, "Thailand daily rainfall and comparison with TRMM products," Journal of Hydrometeorology, vol. 9, no. 2, pp. 256-266, 2008.

[18] M. N. Islam, S. Das, and H. Uyeda, "Calibration of TRMM derived rainfall over Nepal during 1998-2007," The Open Atmospheric Science Journal, vol. 4, no. 1, pp. 12-23, 2010.

[19] Y. Wang, L. Zhou, and K. P. Hamilton, "Effect of convective entrainment/detrainment on the simulation of the tropical precipitation diurnal cycle," Monthly Weather Review, vol. 135, no. 2, pp. 567-585, 2007.

[20] P. Zuidema, "Convective clouds over the bay of Bengal," Monthly Weather Review, vol. 131, no. 5, pp. 780-798, 2003.

[21] L. Qi and Y. Wang, "The effect of mesoscale mountain over the East Indochina Peninsula on downstream summer rainfall over East Asia," Journal of Climate, vol. 25, no. 13, pp. 4495-4510, 2012.

[22] P. J. Webster, E. F. Bradley, C. W. Fairall et al., "The JASMINE pilot study, Bulletin of the American Meteorological Society, vol. 83, no. 11, pp. 1603-1559, 2002.

[23] K. R. Sperber and T. N. Palmer, "Interannual tropical rainfall variability in general circulation model simulations associated with the atmospheric model intercomparison project," Journal of Climate, vol. 9, no. 11, pp. 2727-2750, 1996.

[24] C. Kummerow, W. Barnes, T. Kozu, J. Shiue, and J. Simpson, "The Tropical Rainfall Measuring Mission (TRMM) sensor package," Journal of Atmospheric and Oceanic Technology, vol. 15, no. 3, pp. 809-817, 1998.

[25] C. Kummerow, J. Simpson, O. Thiele et al., "The status of the tropical rainfall measuring mission (TRMM) after two years in orbit," Journal of Applied Meteorology, vol. 39, no. 12, pp. 1965$1982,2000$.

[26] G. J. Huffman, D. T. Bolvin, E. J. Nelkin et al., “The TRMM multi-satellite precipitation analysis (TMPA): quasi-global, multi-year, combined-sensor precipitation estimates at fine scale," Journal of Hydrometeorology, vol. 8, no. 1, pp. 38-55, 2007.

[27] G. J. Huffman, R. F. Adler, D. T. Bolvin, and E. J. Nelkin, "The TRMM multi-satellite precipitation analysis (TMPA)," in Satellite Rainfall Applications for Surface Hydrology, M. Gebremichael and F. Hossain, Eds., chapter 1, pp. 3-22, Springer Netherlands, Rotterdam, The Netherlands, 2010.

[28] G. J. Huffman, "Estimates of root-mean-square random error for finite samples of estimated precipitation," Journal of Applied Meteorology, vol. 36, no. 9, pp. 1191-1201, 1997.

[29] R. F. Adler, G. J. Huffman, A. Chang et al., "The version-2 global precipitation climatology project (GPCP) monthly precipitation analysis (1979-present)," Journal of Hydrometeorology, vol. 4, no. 6, pp. 1147-1167, 2003.

[30] G. J. Huffman, R. F. Adler, M. M. Morrissey et al., "Global precipitation at one-degree daily resolution from multisatellite observations," Journal of Hydrometeorology, vol. 2, no. 1, pp. 3650, 2001.

[31] G. J. Huffman, R. F. Adler, D. T. Bolvin, and G. Gu, "Improving the global precipitation record: GPCP Version 2.1," Geophysical Research Letters, vol. 36, no. 17, Article ID L17808, 2009.

[32] P. P. Xie and P. A. Arkin, "Global precipitation: a 17-year monthly analysis based on gauge observations, satellite estimates, and numerical model outputs," Bulletin of the American Meteorological Society, vol. 78, no. 11, pp. 2539-2558, 1997. 
[33] T. Takemi, O. Hirayama, and C. Liu, "Factors responsible for the vertical development of tropical oceanic cumulus convection," Geophysical Research Letters, vol. 31, no. 11, 2004.

[34] Y. Ogura and M. Yoshizaki, "Numerical study of orographicconvective precipitation over the eastern Arabian Sea and the Ghat Mountains during the summer monsoon," Journal of the Atmospheric Sciences, vol. 45, no. 15, pp. 2097-2122, 1988. 

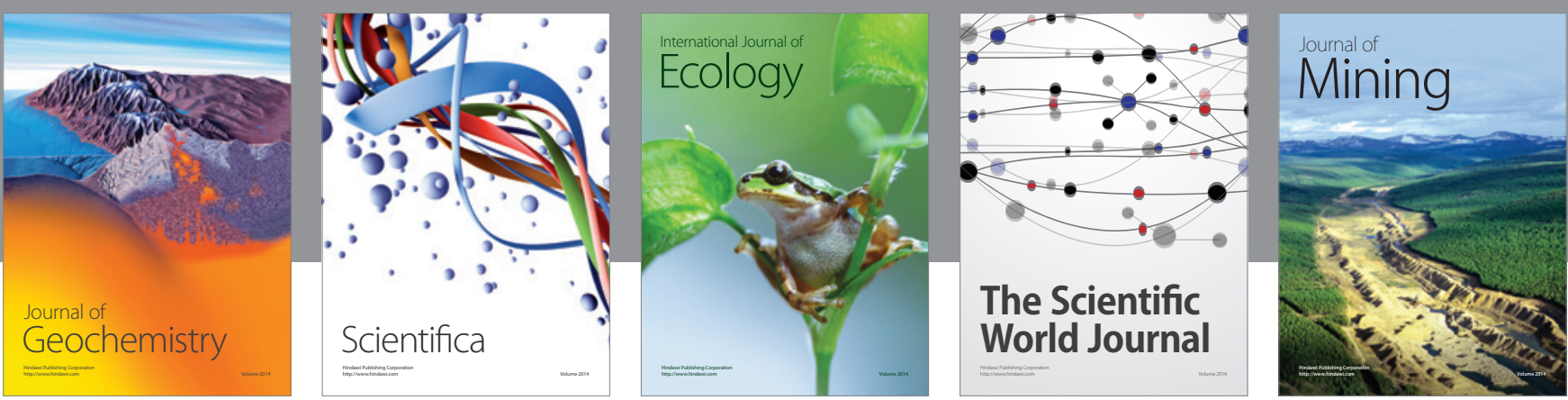

The Scientific World Journal
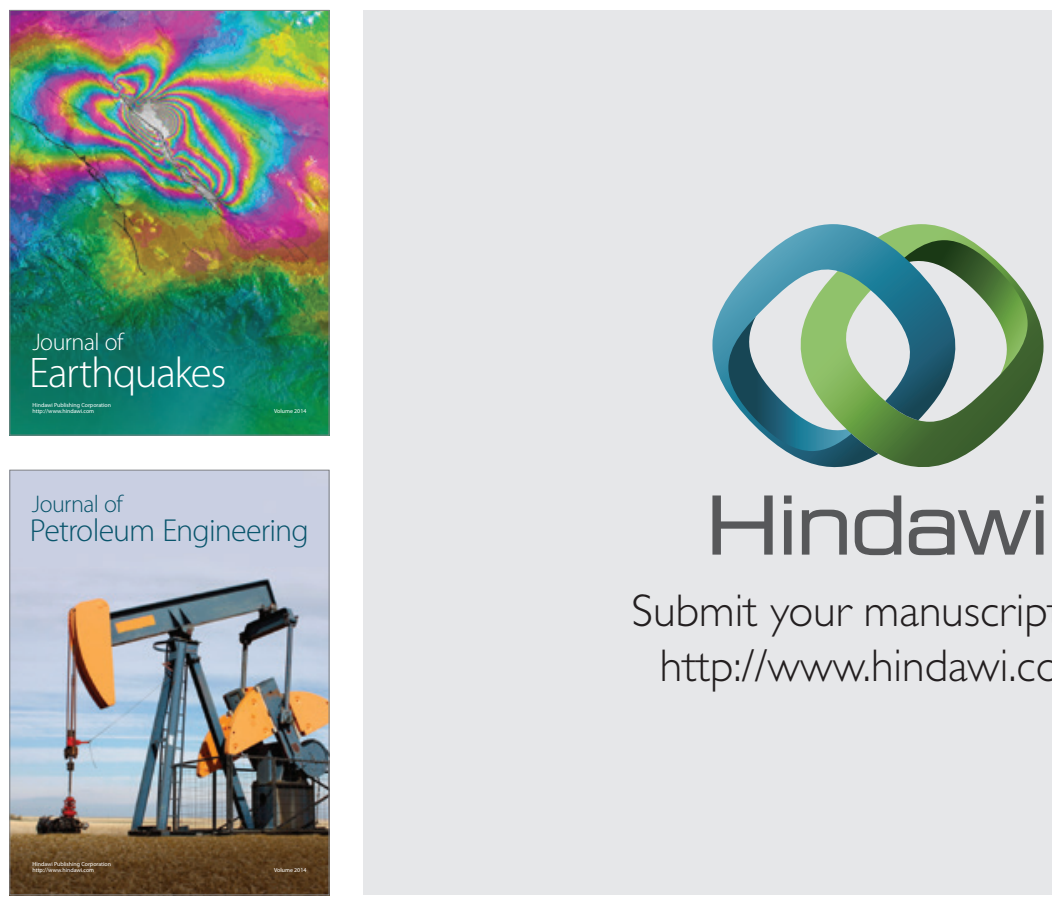

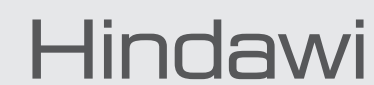

Submit your manuscripts at

http://www.hindawi.com
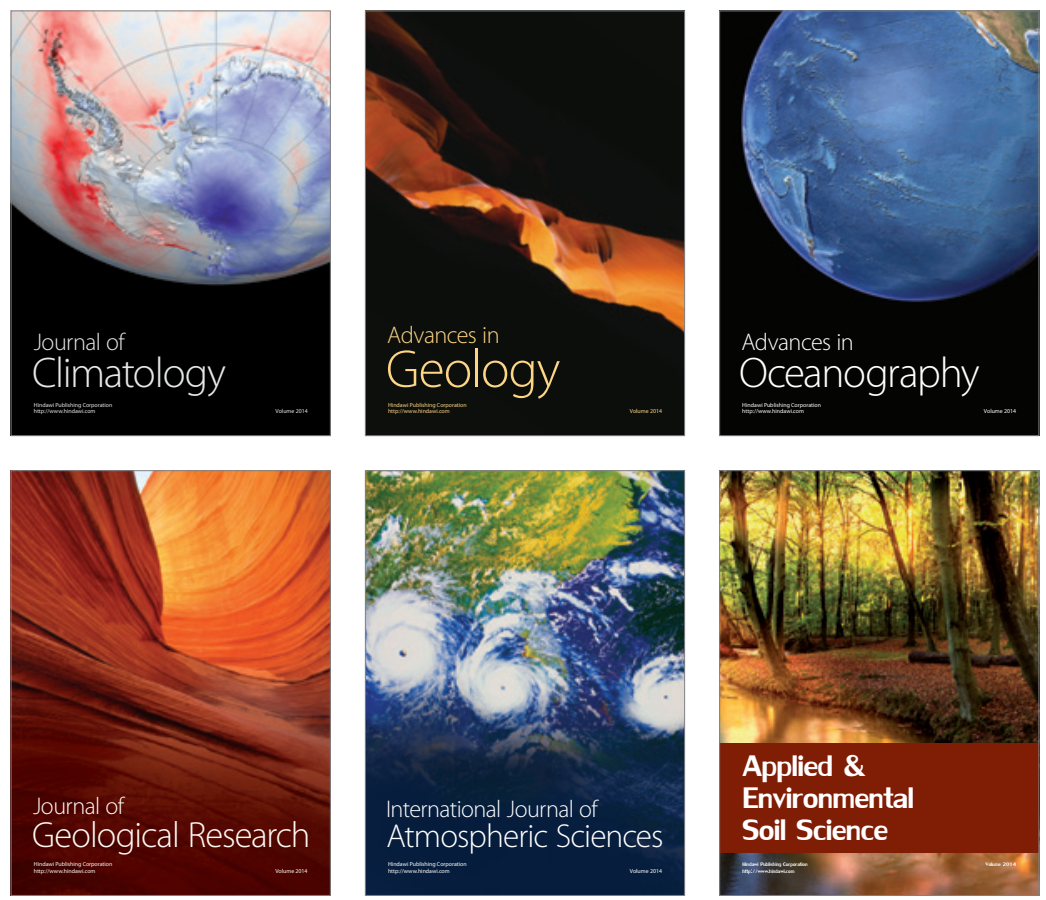
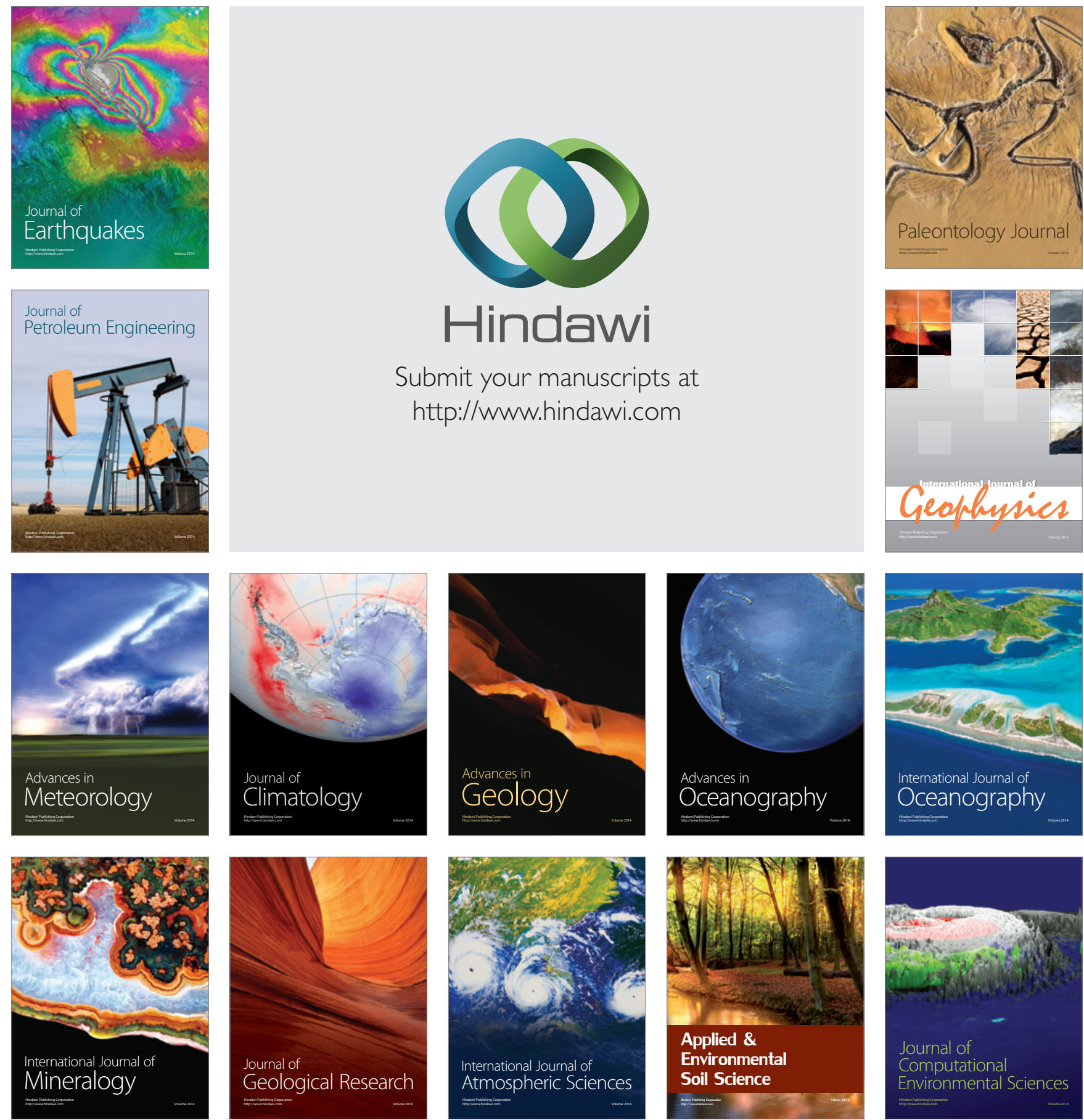